\title{
CONTRIBUIÇÃo DA ESTRATÉGIA DA PRODUÇÃo PARA A ESTRATÉGIA DO NEGÓCIO
}

\author{
J. M. Vilas-Boas da Silva *
}

\section{INTRODUÇÃO}

A estratégia da produção é um elo fundamental da estratégia empresarial que nem sempre tem sido objecto da atenção que merece. Este artigo pretende chamar a atenção para esta realidade, analisar algumas das lacunas existentes e promover a divulgação de uma metodologia de abordagem do tema, com cariz prático.

A actualidade da temática é comprovada pela declaração de objectivos do Programa Estratégico de Dinamização e Modernização da Indústria Portuguesa -PEDIP II, o qual é um instrumento indispensável à implementação da actual política industrial portuguesa. É objectivo do programa o seguinte:

«... dinamizar o crescimento sustentado da competitividade das empresas industriais portuguesas, reforçando a capacidade de resposta às rápidas mutações tecnológicas e de mercados e promovendo a modernização, a diversificação e a internacionalização da estrutura industrial.»

De facto, para que estas intenções possam ser transpostas para a realidade empresarial, é essencial que as organizações desenvolvam um suporte estratégico adequado e eficaz. Este, por um lado, deverá permitir a gestão efectiva do negócio a longo prazo, conferindo-lhe um rumo e uma perspectiva de futuro, orientadora do investimento. Por outro lado, a existência de um enquadramento estratégico potencia as sinergias de uma gestão de curto e médio prazo que integre consistentemente as variadas perspectivas funcionais em torno de objectivos comuns - os da organização vista como um todo — em detrimento, por vezes, e quando necessário, dos interesses específicos das áreas funcionais. A confirmação desta perspectiva é constatada na estruturação do Sistema de Incentivos a Estratégias de Empresas Industriais (SINDEPEDIP), o qual implica que as empre-

\footnotetext{
* Instituto Universitário de Desenvolvimento e Promoção Social - Pólo de Viseu da Universidade Católica Portuguesa.
} 
sas que se candidatem a apoios formalizem «a priori» o seu plano estratégico, como forma de suporte do seu plano integrado de desenvolvimento para os próximos anos.

O presente artigo está estruturado em duas partes. Numa primeira, procuram detectar-se as falhas existentes na implementação dos programas estratégicos das organizações, tratando-se mais detalhadamente os aspectos respeitantes à estratégia da produção. Na segunda parte, começa-se por analisar algumas das áreas de decisão da estratégia da produção. Procura ainda contribuir-se para a divulgação de uma metodologia de abordagem e implementação da estratégia da produção, de modo integrado na estratégia do negócio.

\section{ESTRATÉGIA EMPRESARIAL E ESTRATÉGIA DA PRODUÇÃO}

\subsection{Estratégia empresarial}

\subsubsection{Conceitos-base}

\section{- Estratégia}

Embora existam diversas definições genéricas para o vocábulo estratégia, a maior parte inclui aspectos como estabelecer objectivos, fixar o rumo, desenvolver planos, implementar acções e garantir uma vantagem distinta.

Existe também acordo quanto aos principais pressupostos que se admitem quando o termo se aplica comercialmente: uma estratégia refere-se a um certo horizonte de tempo, deve causar um certo impacto, requere uma concentração de esforço e de recursos num conjunto de actividades que é exclusiva face a outras possibilidades, necessita que seja tomado um conjunto de decisões consistentemente articuladas e finalmente requere perseverança nas actividades a desenvolver. Destacam-se ainda os seguintes aspectos: uma estratégia deve ser apropri$a d a$, na medida em que se adeque à organização, compreensiva, por entender e enquadrar os contributos de todas as sensibilidades, coerente, por compatibilizar as políticas funcionais, eliminando potenciais conflitos e, por fim, credível, por garantir que os objectivos de melhoramento são realistas e alcançáveis.

\section{- Processo estratégico}

Existem variadas estruturas para se agruparem de um modo lógico os diversos estágios resultantes da formulação de uma estratégia. Embora muitas empresas de consultoria tenham os seus métodos próprios, todos tendem a seguir um padrão e uma filosofia comuns, conhecida pela metodologia do "gap» que consta essen- 
cialmente de quatro aspectos. Primeiramente, é necessário determinar-se o que é importante para a organização, através da resposta à questão: Que objectivos? De seguida, é preciso identificar-se claramente a posição actual do negócio e o seu nível de desempenho, através de um estudo de diagnóstico. Determina-se então o "gap» entre o nível de «performance» que se pretende e o existente. É este «gap» que vai liderar, focar e estabelecer prioridades para o processo de melhoramento. Finalmente, as prioridades de desempenho determinam a escolha e implementação dos planos e projectos de melhoramento no curto e no longo prazo.

\subsubsection{Níveis estratégicos}

Nas organizações a implementação de uma estratégia desenvolve-se em três níveis: a estratégia para a organização, a estratégia para os domínios de actividade e a estratégia para as áreas funcionais, consoante se esquematiza na Figura 1.

Fig. 1

\section{NÍVEIS ESTRATÉGICOS}

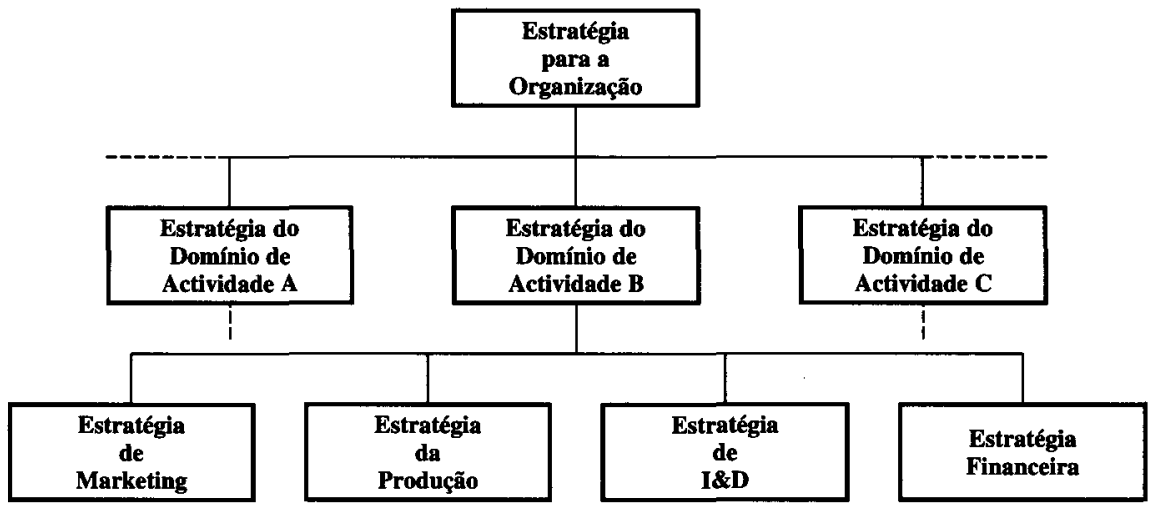

Fonte: Hayes, 1984

No nível mais elevado destacam-se duas áreas de interesse global para a organização: a definição do negócio e a compra e afectação dos recursos-chave aos vários domínios de actividade.

A primeira implica que exista uma identificação da orientação dominante dos domínios de actividade, a qual deverá explicitar a relativa importância das várias funções, bem como o papel que o sistema de fabrico deverá desempenhar na prossecução da estratégia competitiva. Neste estádio, deverão ser identificadas declarações neutrais e/ou negativas sobre o posicionamento do sistema de fabrico, caso se espere deste uma contribuição positiva. 
A segunda é tipicamente responsável pela aquisição dos recursos financeiros, pela respectiva afectação aos vários domínios de actividade e pela orçamentação requerida.

Como exemplos das principais estratégias empresariais, citam-se o crescimento, a manutenção, o abandono, o «harvest» e o «turn around».

As estratégias para os domínios de actividade que são, usualmente, ou subsidiárias, ou divisões, ou ainda linhas de produto dentro das organizações, especificam o âmbito do negócio, de modo a que este se enquadre na estratégia da organização como um todo. Especificam também o suporte para o alcance e a manutenção da vantagem competitiva do domínio.

A especificação do âmbito do negócio implica a identificação clara dos subsegmentos, produto/mercado/serviço, de interesse para o domínio, o que promove a focagem do negócio e evita a potencial concorrência entre diferentes domínios da organização.

A liderança de custos e a diferenciação são duas das principais estratégias que se utilizam para os domínios de actividade.

$O$ terceiro nível estratégico compreende as estratégias funcionais. Uma vez desenvolvida a estratégia para o domínio de actividade, cada área funcional deverá identificar uma estratégia que a suporte. Para ser eficaz, cada estratégia funcional deve apoiar, através de um conjunto de decisões consistentemente articuladas, a estratégia do domínio de actividade. Por outro lado, a estratégia funcional deve distinguir actividades verticais e horizontais. Enquanto que as primeiras se referem às relações hierárquicas organizacionais clássicas, as segundas relacionam-se com múltiplas funções. Constituem exemplos das últimas os procedimentos de melhoria da qualidade, o desenvolvimento de produtos e os projectos de engenharia de larga escala.

\subsection{Estratégia da produção}

As empresas industriais investem no desenvolvimento da sua estrutura (processo e tecnologia) e infra-estrutura (pessoas, sistemas e procedimentos), tendo em vista fabricar produtos e prestar serviços que permitam obter um retorno compensador, não só em termos financeiros. Contudo, nem sempre o aparelho produtivo é visto de forma positiva, como uma vantagem competitiva que a organização possui e que lhe permite impor-se à concorrência. Por vezes, é entendido como algo somenos importante que apenas serve para empatar capital e recursos.

Por outro lado, na maior parte das empresas industriais constata-se que a estratégia da produção é incapaz de suportar, de forma explícita e efectiva, a evolução do negócio de acordo com as directrizes emanadas, as limitações impostas e os 
caminhos escolhidos. Esta situação deve-se a vários aspectos que nos propomos rever em seguida.

\subsubsection{A Evolução do contexto de inserção das empresas industriais}

A função produção viu definitivamente confirmada a perda de prestígio do seu estatuto, na década de 70, a seguir ao choque petrolífero. Em paralelo com este, verificou-se uma grande recessão que, em conjunto com a tendência de crescimento da capacidade disponível, facilmente amplificou o fenómeno de afirmação da capacidade excedentária, face à procura que estava já em curso, desde meados da década de 60 . Este processo de mudança da envolvente foi acompanhado, internamente nas organizações, por uma valorização das funções financeira $e$ comercial, em detrimento da produção, até então predominante.

Ainda na década de 80 e especialmente nas anteriores era vulgar, quer na produção, quer nas restantes áreas funcionais, existir uma cultura de maximização dos objectivos sectoriais em detrimento da procura da optimização do conjunto, isto é do negócio. Este aspecto reflectia-se de forma preocupante nas interfaces funcionais, criando lacunas nas relações e no entendimento dos vários sectores. Não é, pois, de estranhar que se tenha vindo a manifestar uma ausência de ligação entre as estratégias de marketing e da produção.

Somente desde há poucos anos esta tendência tem vindo a inverter-se, por força da pressão da concorrência e das suas novas formas de manifestação, nomeadamente a globalização do mercado, factores que obrigam a uma optimização da gestão das empresas. Também, em termos externos, a pressão dos accionistas e dos consumidores e as elevadas taxas de introdução de novas tecnologias e, em termos internos, a força de trabalho, têm gerado uma necessidade de mudança interna de procedimentos, com vista ao alcance da racionalização e da optimização do desempenho global das empresas.

\subsubsection{A função gestão da produção}

Durante 50 anos a gestão da produção baseou-se nos especialistas em eficiência, treinados nas técnicas de Frederik W. Taylor: seleccionar uma operação, dividi-la em elementos, analisar e melhorar cada elemento e reagrupá-los de novo. Os engenheiros industriais eram então os reis da fábrica

Durante a sua predominância, a função produção estava orientada internamente para os aumentos de produtividade e para o ritual de glorificação do produto «de per si». Ignorava os clientes e a orientação para o mercado e sobrevalorizava o ponto de vista da engenharia, focado nas ferramentas, equipamentos e processo de 
fabrico. A era da cultura da engenharia industrial causava o mal estar de muitos gestores de topo, que se sentiam incompetentes e desqualificados para se envolverem nas decisões respeitantes às ditas porcas e parafusos. Muitas vezes, porém, era a própria gestão de topo a responsável pelo corte com a fábrica e pela demissão dos seus deveres, mediante o argumento de que a empresa tinha especialistas na produção que eram muito bem pagos e que deviam ser capazes de executar a sua função, sem incomodar os gestores de primeira linha.

No seu isolamento, os engenheiros industriais restringiam o seu conhecimento e compreensão dos fenómenos de mercado e da estratégia do negócio e, consequentemente, limitavam as suas possibilidades de subida na hierarquia da organização. $O$ seu modo de estar primava pela ausência de uma gestão estruturada e abrangente, em que se integrasse a concepção dos sistemas de fabrico nas políticas funcionais e em que tudo isto fosse coerente com a definição dos objectivos-chave e com a estratégia para o domínio.

Tradicionalmente, o gestor da produção ou, pura e simplesmente, não era educado e treinado para o desempenho da sua actividade, ou era inadequadamente formado. Verificava-se, nesta função, uma orientação para as questões técnicas, caracterizada por uma actuação reactiva e limitada nos seus horizontes, quer temporais, quer físicos. Esta postura também resultava do facto da empresa promover automaticamente operários a encarregados, encarregados a gestores e estes a directores, implicitamente aceitando um papel reactivo e secundário dos responsáveis pela fábrica. Consequentemente, estes tendiam a isolar-se e a evitar a participação no processo de tomada de decisão de alto nível. Por outro lado, o ensino nas universidades, quando existia, caracterizava-se pela divulgação de uma série de métodos e técnicas de engenharia industrial (estudo dos métodos e tempos, layout, estudo dos fluxos, teoria do lote económico, métodos de ponto de encomenda, etc) $e$ de análise quantitativa (programação linear, simulação, teoria das filas de espera, etc), o que contribuía para a ausência da visão sistémica da empresa.

$\mathrm{Na}$ concertação de estratégias globais e envolventes de todas as áreas funcionais tomam particular importância os processos de comunicação e de negociação. Salienta-se, no entanto, a ausência de tradição, por parte dos gestores da produção, de funcionar de modo orientado para o negócio, de explicar aos outros a sua função, de estabelecer e explorar cenários alternativos e de defender as opções que claramente seja demonstrado serem as mais satisfatórias. Daqui resultam importantes lacunas na linguagem e toda uma série de mal-entendidos que ameaçam a participação, de pleno direito e de superior interesse, dos representantes da produção na gestão do negócio.

Como agravante dos aspectos anteriormente referidos, tem-se também verificado uma grave falha no reconhecimento das trocas envolvidas na gestão do aparelho produtivo. Nomeadamente, é vulgar constatar-se a ignorância e o desprezo 
pelos compromissos que as variáveis custo, tempo, quantidades, tecnologias e satisfação do cliente forçam. Estes compromissos limitam a actividade de gestão e exigem uma explícita aceitação de uma enormidade de trocas e escolhas que o Quadro I ilustra.

\section{Quadro I}

\section{COMPROMISSOS REFERENTES AO SISTEMA DE FABRICO}

\begin{tabular}{|c|c|c|}
\hline Área de Decisão & Decisão & Alternativas \\
\hline Fábrica e equipamento & $\begin{array}{l}\text { Extensão do processo } \\
\text { Dimensão da fábrica } \\
\text { Localização da fábrica } \\
\text { Investimento } \\
\text { Selecção, troca e aprovisionamento } \\
\text { de ferramentas }\end{array}$ & $\begin{array}{l}\text { Fazer ou comprar } \\
\text { Uma fábrica grande ou várias pequenas } \\
\text { Próxima dos mercados ou das matérias-primas } \\
\text { Investir principalmente em edifícios, ou equi- } \\
\text { pamentos, ou inventários, ou I\&D } \\
\text { Uso temporário, troca mínima ou «set up» per- } \\
\text { manente }\end{array}$ \\
\hline Planeamento e controle da produção & $\begin{array}{l}\text { Frequência de utilização de } \\
\text { inventários } \\
\text { Dimensão do inventário } \\
\text { Nível de controle } \\
\text { Que controlar? }\end{array}$ & $\begin{array}{l}\text { Muitas ou poucas paragens na produção com } \\
\text { recurso aos «stocks» de segurança } \\
\text { Baixos ou elevados níveis de «stocks» } \\
\text { Maior ou menor detalhe de controle } \\
\text { Controle concebido para minimizar tempo de } \\
\text { avarias, custo do trabalho, tempo de proces- } \\
\text { samento, ou para maximizar o coutput» de } \\
\text { certos produtos ou consumos de materiais } \\
\text { Elevado nível de fiabilidade e de qualidade ou } \\
\text { custos directos baixos } \\
\text { Formal, informal ou nenhum }\end{array}$ \\
\hline Recursos humanos & $\begin{array}{l}\text { Especialização } \\
\text { Supervisão } \\
\text { Sistema de remuneração } \\
\text { Engenheiros industriais }\end{array}$ & $\begin{array}{l}\text { Muito ou pouco especializado } \\
\text { Treino ou não dos supervisores de } 11^{a} \text { linha; } \\
\text { supervisão apertada ou resposabilização } \\
\text { Muitos ou poucos níveis; bónus ou salários à } \\
\text { hora } \\
\text { Muitos ou poucos }\end{array}$ \\
\hline Concepção/engenharia & $\begin{array}{l}\text { Dimensão da linha de produtos } \\
\text { Estabilidade do projecto } \\
\text { Risco tecnológico } \\
\text { Engenharia } \\
\text { Engenheiros de processo }\end{array}$ & $\begin{array}{l}\text { Muitos, poucos ou nenhuns produtos especiais } \\
\text { Possibilidade de mudanças ou congelamento } \\
\text { do projecto } \\
\text { Uso de novos processos não testados pelos } \\
\text { concorrentes, ou política de seguimento do } \\
\text { líder. } \\
\text { Package com projecto completo ou projecto } \\
\text { faseadamente desenvolvido } \\
\text { Poucos ou muitos }\end{array}$ \\
\hline Organização e gestão & $\begin{array}{l}\text { Tipo de organização } \\
\text { Uso do tempo dos executivos } \\
\text { Nível de risco assumido } \\
\text { Uso do «staff» } \\
\text { Estilo executivo }\end{array}$ & $\begin{array}{l}\text { Funcional, ou por produto, ou geográfica, ou } \\
\text { com foco no processo } \\
\text { Grande envolvimento nos investimentos, pla- } \\
\text { neamento da produção, controle de custos, } \\
\text { controle da qualidade, ou outras actividades } \\
\text { Muita ou pouca informação de apoio à tomada } \\
\text { de decisão } \\
\text { Grupo grande ou pequeno } \\
\text { Muito ou pequeno envolvimento com deta- } \\
\text { lhes; estilo autoritário ou não directivo; } \\
\text { grande ou pequeno contacto com a organi- } \\
\text { zação }\end{array}$ \\
\hline
\end{tabular}


Finalmente, salienta-se a falta de interesse e de motivação das restantes áreas funcionais para escutar e entender a produção, correntemente percepcionada como desinteressante, rotineira, baseando-se em procedimentos standardizados, pouco sofisticada e pouco atractiva para trabalhadores, técnicos e gestores. O Quadro II mostra os reflexos deste entendimento da função produção sobre as preferências de carreira profissional dos estudantes.

\section{Quadro II}

PREFERÊNCIAS DE CARREIRA PROFISSIONAL

\begin{tabular}{|l|c|c|c|}
\hline \multicolumn{1}{|c|}{$\begin{array}{c}\text { Carreiras consideradas } \\
\text { pelos estudantes }\end{array}$} & $\begin{array}{c}\text { Total } \\
\%\end{array}$ & $\begin{array}{c}\text { Homens } \\
\%\end{array}$ & $\begin{array}{c}\text { Mulheres } \\
\%\end{array}$ \\
\hline Media/Comunicações & 30 & 28 & 33 \\
Educação & 28 & 24 & 34 \\
Banca e Finanças & 19 & 20 & 17 \\
Computação/Tecnologia de Informação & 17 & 24 & 8 \\
Turismo/Lazer & 16 & 12 & 22 \\
Engenharia & 15 & 22 & 4 \\
Administração Pública & 15 & 14 & 17 \\
Juristas & 14 & 11 & 18 \\
Contabilidade & 14 & 15 & 13 \\
Retalho & 10 & 7 & 14 \\
Autarquias & 9 & 9 & 8 \\
Empresas de Energia & 9 & 13 & 3 \\
Medicina/Dentistas & 8 & 7 & 10 \\
Produção & 7 & 9 & 3 \\
Nenhum & 6 & 5 & 8 \\
\hline
\end{tabular}

Fonte:Student Attitudes to British Business, estudo realizado pelo Research Surveys of Great Britain, Research Centre, West Gate, London W5 1EL, citado no Financial Times, de 14/07/89.

Verifica-se no Quadro II que as preferências pela produção representam a última das opções dos jovens na Grã-Bretanha. É significativo, preocupante e sugere que é necessário fazer algo, a fim de se evitar a falha na atracção de novos talentos.

Em conclusão, destaca-se a ausência da dimensão estratégica, na forma como a função produção tem sido gerida, com a correspondente indiferença pela participação na gestão do negócio e pela valorização dos horizontes de longo prazo. São também ignoradas as interfaces funcionais, em favor de uma focagem exagerada e extremamente limitada na transformação física que, por vezes, ignora compromissos fundamentais. 


\subsubsection{Ferramentas analíticas e metodologia}

O desinteresse dos teóricos pela estratégia da produção constata-se, quer pela escassa bibliografia que é dedicada ao assunto, quer pela reduzida atenção que lhe é facultada nas obras de estratégia empresarial.

Por outro lado, existem poucas ferramentas de análise e constata-se a ausência de uma metodologia, isto é, não está estabelecido um conjunto de conceitos básicos que possibilitem a fundamentação de uma abordagem fỉlosófica, bem como a fixação dos métodos e procedimentos a utilizar.

Ferramentas e técnicas clássicas, tradicionalmente usadas pela engenharia industrial, como o estudo dos métodos e tempos, bem como as técnicas de investigação operacional, têm sido apontadas como a resposta à falta de sofistiticação e de uma base científica da gestão da produção. Contudo, estas ferramentas destinam-se essencialmente à resolução de problemas pontuais de optimização de uma faceta da organização (perspectiva «bottom up») e não desta como um todo. A sua utilidade deverá portanto ser decidida pelos gestores, consoante as operações que pontualmente se pretendam ver optimizadas.

$\hat{E}$ pois necessário que se dinamizem novas competências e novas atitudes na gestão do aparelho produtivo, que constituam um novo elemento com uma implicação relevante na estratégia do negócio. Entre estas, tem assumido destaque $a$ perspectiva «top down», baseada no reconhecimento de que a produção pode ser um destacado instrumento de melhoramento da competitividade, devendo a sua estratégia estar integrada na do respectivo domínio de actividade que, por sua vez, deverá suportar a estratégia para o negócio.

\subsection{A interface produção-«marketing»}

Tradicionalmente, no âmbito do contexto anteriormente traçado, a gestão da produção caracteriza-se por ser uma função fortemente criticada, isolada do todo que constitui a empresa, tacticamente focada na redução arbitrária de custos $e$ com uma fraca margem de manobra.

Os seus gestores são normalmente impotentes para implantarem um processo de mudança racional que responda às exigências da organização, dada, quer a sua posição no seio da empresa, quer a ausência de ferramentas de suporte à função, quer ainda o seu perfil clássico.

De entre os diversos choques característicos entre as várias sensibilidades no interior da empresa, destaca-se o que ocorre entre a produção e o «marketing», como paradigmático dos desacordos mais frequentes e delicados, entre pares de áreas funcionais, e que representa uma das questões relevantes a serem solucionadas pelo desenvolvimento de uma correcta estratégia para os domínios de acti- 
vidade (2. ${ }^{\circ}$ nível estratégico). O Quadro III ilustra algumas das vertentes deste choque.

\section{Quadro III}

INTERACÇÃO FUNCIONAL ENTRE O «MARKETING» E A PRODUÇÃO

\begin{tabular}{|c|c|c|}
\hline Área do problema & $\begin{array}{l}\text { Comentário típico do } \\
\text { «marketing» }\end{array}$ & $\begin{array}{l}\text { Comentário típico } \\
\text { da produção }\end{array}$ \\
\hline $\begin{array}{l}\text { Planeamento da capacidade e } \\
\text { previsão de vendas a longo } \\
\text { prazo }\end{array}$ & $\begin{array}{l}\text { Por que razão a capacidade } \\
\text { não é suficiente? }\end{array}$ & $\begin{array}{l}\text { Por que razão não foi confe- } \\
\text { rida maior precisão às previ- } \\
\text { sões de vendas? }\end{array}$ \\
\hline $\begin{array}{l}\text { Sequenciamento e previsão de } \\
\text { vendas a curto prazo }\end{array}$ & $\begin{array}{l}\text { Precisamos de uma resposta } \\
\text { mais rápida. Os prazos de } \\
\text { entrega são ridículos. }\end{array}$ & $\begin{array}{l}\text { Necessitamos de compromis- } \\
\text { sos realistas por parte dos } \\
\text { clientes e de previsões de } \\
\text { vendas que não variem com } \\
\text { o vento. }\end{array}$ \\
\hline Entrega e distribuição & $\begin{array}{r}\text { Por que razão não temos os } \\
\text { artigos certos em armazém? }\end{array}$ & $\begin{array}{l}\text { Não podemos ter todos os arti- } \\
\text { gos em «stock». }\end{array}$ \\
\hline Garantia de qualidade & $\begin{array}{l}\text { Por que razão não podemos ter } \\
\text { uma qualidade razoável a um } \\
\text { custo razoável? }\end{array}$ & $\begin{array}{l}\text { Por que razão devemos sem- } \\
\text { pre oferecer opçðes muito } \\
\text { difíceis para a produção e de } \\
\text { pequena utilidade para o cli- } \\
\text { ente? }\end{array}$ \\
\hline $\begin{array}{l}\text { Dimensão da linha de produ- } \\
\text { tos }\end{array}$ & $\begin{array}{l}\text { Os nossos clientes exigem } \\
\text { variedade. }\end{array}$ & $\begin{array}{l}\text { A gama de produtos é muito } \\
\text { larga, o que implica o } \\
\text { fabrico de lotes de pequena } \\
\text { dimensão e que não são eco- } \\
\text { nómicos. }\end{array}$ \\
\hline Controle de custos & $\begin{array}{l}\text { Os nossos custos são tão ele- } \\
\text { vados que comprometem a } \\
\text { nossa competitividade. }\end{array}$ & $\begin{array}{l}\text { Não podemos facultar prazos } \\
\text { curtos, variedade, resposta } \\
\text { rápida a mudança e quali- } \\
\text { dade elevada a baixos cus- } \\
\text { tos. }\end{array}$ \\
\hline Introdução de novos produtos & $\begin{array}{l}\text { Os novos produtos são o nosso } \\
\text { sangue, isto é, são-nos essen- } \\
\text { ciais. }\end{array}$ & $\begin{array}{l}\text { Mudanças desnecessárias na } \\
\text { concepção são proibitiva- } \\
\text { mente caras. }\end{array}$ \\
\hline $\begin{array}{l}\text { Serviços auxiliares: «stocks» } \\
\text { de sobressalentes, apoio apos- } \\
\text {-venda, instalação e reparação }\end{array}$ & $\begin{array}{l}\text { O custo dos serviços no cliente } \\
\text { são excessivos. }\end{array}$ & $\begin{array}{l}\text { Os produtos são usados para } \\
\text { fins diferentes dos especifi- } \\
\text { cados. }\end{array}$ \\
\hline
\end{tabular}


A análise, de modo isolado, de cada um dos problemas enumerados no Quadro III não seria a abordagem ideal para que se resolvessem as questões anteriormente colocadas, pois dificilmente conduziria a uma harmonização entre as sensibilidades em confronto. Em alternativa, deve utilizar-se uma perspectiva de carácter global em que importa solucionar as divergências entre as exigências colocadas à produção pelo «marketing» $e$ a capacidade do sistema de fabrico. Uma perspectiva interessante para a abordagem do problema baseia-se na análise da interaç̧ão dos ciclos de vida dos produtos e dos sistemas de fabrico. Esta abordagem pode ser completada pela análise da relação entre os critérios que promovem a angariação de encomendas, nos segmentos de mercado em que os produtos estão, e a sua satisfação pelo sistema de fabrico da empresa.

Contudo, da observação do Quadro III conclui-se ainda que tem sido tradição, em vez de se ter um conjunto de políticas coerentes e consistentes, todas focadas, convergindo numa direç̧ão e mutuamente suportadas, terem-se perspectivas conflituosas e interesses cruzados específicos, divergentes internamente.

Por outro lado, a tentativa e a tentação de se servirem $n$ mercados, de se usarem $n$ tecnologias e de se terem $n$ requisitos estratégicos, dentro de uma só fábrica, poderá resultar numa perda de foco, por impossibilidade de se definirem os critérios que permitem determinar o que é de facto importante. Reconhece-se portanto que a estratégia competitiva de uma empresa, para um dado produto, num dado mercado e num dado momento, coloca exigências particulares ao sistema de fabrico e reconhece-se ainda que as estratégias e as políticas de produção e operações devem ser especificamente concebidas para satisfazer as tarefas exigidas pelos planos estratégicos do domínio de actividade e do negócio.

\subsection{Integração da estratégia da produção dos SBU's na estratégia empresa- rial}

Na situação de uma empresa com vários SBU's («Strategic Business Units») é pertinente questionar o ponto de equilíbrio entre uma estratégia da produção comum a todos os $S B U$ 's, o que facilitaria muito os mecanismos de controle, mas perderia consideravelmente em termos de foco e, no outro extremo, estratégias da produção independentes para as várias áreas de negócio, mesmo sendo estas similares. Aliás, há quem defenda que, muitas vezes, a perda da vantagem competitiva das multinacionais nos mercados externos, em favor das comparativamente pequenas empresas nacionais, se deve precisamente a uma prepotente centralização de estratégias, procedimentos e políticas.

A solução de compromisso mais racional advoga uma separação entre as áreas de decisão central e aquelas que devem ser tomadas localmente. As primeiras serão necessariamente de carácter mais genérico, podendo ser ilustradas 
pelas decisões quanto à especificação da dimensão e localização das instalações fabris, por determinadas políticas de pessoal e de justificação do investimento, pelo formato de certos relatórios que deverão ser consolidados superiormente (por exemplo, custos e qualidade), pelo processo de investigação e desenvolvimento comum do sistema de fabrico, entre muitas outras. No entanto, não é fácil estabelecer que decisões serão incluídas em cada um dos grupos. A escolha poderá variar consideravelmente de uma organização para outra.

\subsection{Síntese do parágrafo}

No decurso deste artigo, têm-se vindo a referir alguns dos aspectos que têm contribuído para a exclusão da estratégia da produção face à estratégia do negócio, nomeadamente, factores de carácter interno, do âmbito da função produção e outros da responsabilidade da sua envolvente, isto é, afectos à gestão do negócio e à interface com outras áreas funcionais, como é o caso do «marketing».

Esperamos ter demonstrado que a ênfase na função produção bem sucedida, essencial ao suporte da faceta competitiva do negócio de raiz industrial, implica uma participação activa nos assuntos de carácter estratégico.

Conhecido o histórico da situação actual da função produção e do seu enquadramento, isto é, os seus pontos fortes e fracos, é importante que sejam os gestores do aparelho produtivo a tomarem a iniciativa de dinamização do processo de mudança, lutando contra a inércia institucional, na certeza de que também é necessário implementar as acções certas, para além destas se desenvolverem correctamente.

Há pois que mudar a perspectiva actual de que «a produção é mal ensinada nas escolas, mal entendida pela gestão de topo e mal gerida na fábrica».

\section{ESTRATÉGIA INTEGRADA DA PRODUÇÃO}

\subsection{Elementos principais}

Apresentam-se, de seguida, os principais factores de decisão a ter presentes durante a definição de uma estratégia da produção. Estes factores estão divididos em dois grupos. Os estruturais são aqueles que têm um impacto a longo prazo, são dificilmente reversíveis ou anuláveis, uma vez implantados e requerem um investimento em capital considerável para se expandirem ou reformularem. $O s$ infra-estruturais são considerados mais tácticos, dado que requerem decisões con- 
tinuadas durante a sua execução, estão ligados a aspectos operacionais do negócio e, geralmente, não requerem investimentos visíveis em capital, quando comparados com os aspectos estruturais. Contudo, também podem exigir o dispêndio de somas consideráveis para expansão ou reformulação.

\section{- Estruturais}

1. Capacidade (dimensão, «timing» e tipo)

2. Instalações (dimensão, localização e especialização)

3. Tecnologia (equipamento, automação e ligações)

4. Integração vertical (direcção, extensão e balanceamento)

\section{- Infra-estruturais}

5. Recursos humanos (competências, salários e segurança do emprego)

6. Qualidade (prevenção de defeituoso, monitoria e intervenção)

7. Planeamento da produção/controle de materiais (fornecedores, centralização e regras de decisão)

8. Organização (estrutura, sistemas de controle/pagamento e regras de desempenho)

Estes oito factores estão interrelacionados. Por exemplo: a capacidade anual de uma fábrica depende da manutenção da taxa de produção; as políticas para a força de trabalho interagem com a escolha do processo de fabrico; as políticas de compras dependem das opções de integração vertical; a concepção da organização interage com as decisões de integração vertical, assim como se relaciona com a localização das fábricas, a sua especialização e as suas ligações.

É o conjunto das decisões nestas oito áreas que constitui a estratégia da produção. É crítico que estas decisões, embora tomadas em diversos níveis através da organização, sejam consistentes entre si e, também, relativamente a outras tomadas noutros períodos de tempo e eventualmente por outros elementos da estrutura. Por outro lado, o efeito cumulativo de todo este processo decisional deverá concretizar-se na estrutura e infra-estrutura desejadas, bem como num conjunto de capacidades e competências específicas que permitam ao negócio prosseguir a sua estratégia competitiva a longo prazo.

\subsection{Análise dos elementos estruturais}

Neste artigo, não se detalharão os factores infra-estruturais, pois eles são mais correntemente objecto de atenção e divulgação, ao contrário do que acontece com os elementos estruturais. 
Muitas empresas confundem o conceito de Estratégia da Produção com Estratégia da Capacidade. Como indicado previamente, embora a capacidade seja um componente importante da Estratégia da Produção, a sua abordagem constitui apenas o primeiro passo desta. Vamos, de seguida, passar a clarificar estes aspectos.

\subsubsection{Capacidade}

\subsubsection{Aspectos gerais}

A Estratégia da Capacidade difere de decisões pontuais de expansão, dado que faculta um enquadramento para a globalidade das decisóes a longo prazo, analisando os diferentes cenários possíveis, face a aspectos como:

- crescimento estimado e variabilidade da procura

- custo de construção e operação de diferentes fábricas

- tendências de evolução tecnológica

- impacto do comportamento da concorrência, mercados e fornecedores

O dimensionamento da capacidade requer uma análise cuidada das necessidades em recursos e da sua disponibilidade, em particular em relação aos críticos. Mais do que desenhar uma linha num gráfico, há que garantir a efectiva implementação das acções planeadas. $O$ conceito de economias de escala poderá desempenhar um papel crítico no dimensionamento da capacidade.

As economias de escala resultam da constatação prática de que os custos de produção crescem a uma taxa inferior à do volume de produção, até um determinado ponto. A partir daí verifica-se o fenómeno inverso, isto é, as «deseconomias" de escala. Estas podem ser de diversos tipos, sendo os mais conhecidos a distribuição, a burocratização, a confusão e a vulnerabilidade ao risco.

$\mathrm{O}$ «timing» para as mudanças de capacidade depende da evolução do comportamento da procura e da política da empresa. As três políticas mais comuns são as seguintes:

Excesso de capacidade:

a empresa desenvolve e mantém capacidade extra, de modo a evitar roturas, por analogia com o papel desempenhado pelo «stock» de segurança na gestão de existências; contudo, a sobrecapacidade tem um risco de obsolescência menor; 
À medida das necessidades:

a empresa mantém a capacidade balanceada com a procura, de modo a que seja totalmente utilizada; se, por um lado, não se incorre em custos de sobrecapacidade, por outro, poderá ter que se subcontratar em períodos de acréscimo de vendas;

Maximização da utilização: a capacidade da empresa acompanha a evolução da procura por defeito; assegura-se assim uma utilização máxima e um investimento mínimo, o que conduz à maximização do retorno; o risco assumido é uma potencial perda de quota de mercado.

Entre os vários tipos de capacidade destaca-se a denominada capacidade de amortecimento. Esta pode ser constituída pelos inventários. De facto, a manutenção de "stocks» faculta a resposta mais rápida à procura, embora implique riscos mais elevados. O nível de existências depende de aspectos como a rapidez de resposta, o custo, a flexibilidade, a obsolescência, o nível de roturas e o tipo de negócio.

A capacidade de amortecimento pode também ser constituída por fundos financeiros, que são de dois tipos: gerais ou específicos. Enquanto os gerais são constituídos por capital existente sem uma finalidade única ou particular, os específicos são fundos reservados exclusivamente para investimento na fábrica e em equipamentos quando necessário.

\subsubsection{Planeamento}

Normalmente, o planeamento da capacidade realiza-se em função do horizonte temporal, consoante expresso na Figura 2.

Neste parágrafo, apenas se tecerão algumas considerações referentes ao planeamento do aprovisionamento dos recursos produtivos (instalações e equipamentos, força de trabalho e materiais), a longo prazo.

Relativamente à aquisição e disposição do espaço físico e dos equipamentos significativos, deverão seleccionar-se as potencialidades requeridas, tomar decisões sobre localizações e «timings» e, finalmente, determinar o montante em capital a dispender.

Quanto aos recursos humanos é necessário definir as políticas de contratação e de despedimento, as competências requeridas, os programas de formação e treino e, por fim, decidir sobre os «timings» e as quantidades. 
Fig. 2

PLANEAMENTO DA CAPACIDADE E HORIZONTES TEMPORAIS

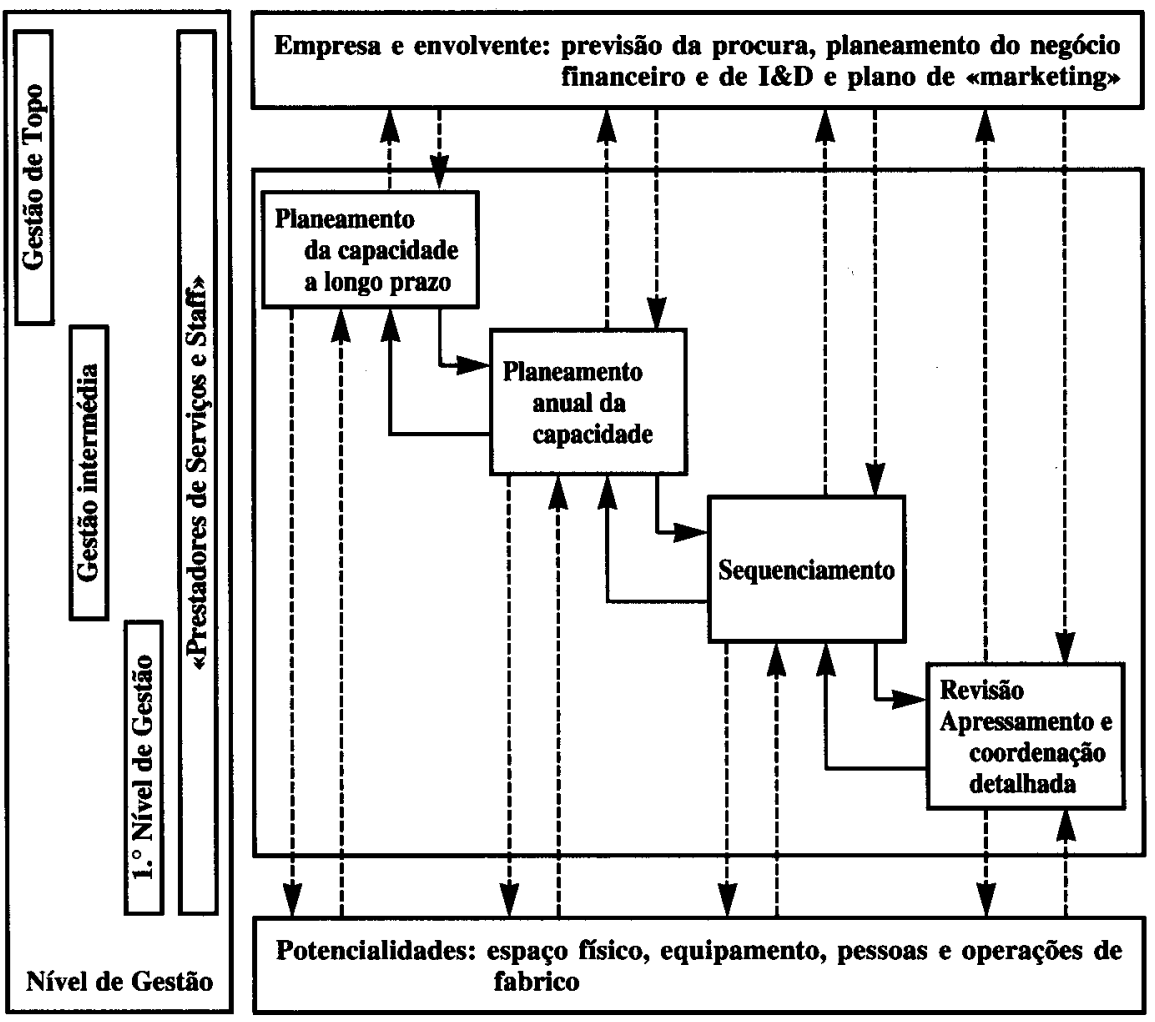

Fonte: Adaptado de Note on Capacity Management, Harvard Case Services, 9, 974-981

No que se refere aos materiais, é conveniente determinar as necessidades respectivas, seleccionar fornecedores, negociar contratos a longo prazo, calcular os requisitos de armazenamento e decidir, ainda, sobre «timings» e quantidades.

\subsubsection{Instalações}

A estratégia e as decisões referentes às instalações são um dos componentes da estratégia da capacidade que, pela sua relevância, merecem um tratamento personalizado. Na prática, poucas empresas exibem uma abordagem estratégica destes assuntos. Esta postura é apenas uma consequência da atitude reactiva assumida 
pelas organizações neste domínio, em que se deixa que os acontecimentos liderem e forcem o processo de tomada de decisão.

De seguida, vão analisar-se de um modo relacionado as três principais vertentes relativas às instalações - dimensão, localização e especialização —, embora sejam colocadas diferentes ênfases nestes aspectos ao longo da exposição.

\subsubsection{Dimensionamento}

Em empresas com elevadas taxas de crescimento, em que é difícil obter projecções correctas das necessidades, o dimensionamento das instalações é realizado com base na estimativa de certas rácios críticas, tais como: a área por empregado, as vendas por empregado, ou as vendas por unidade de área. $\mathrm{O}$ objectivo é facultar instalações suficientes para o alcance das metas de vendas a longo prazo.

\subsubsection{Localização}

A localização é um aspecto fundamental quando os custos de transporte assumem uma parcela significativa do custo de distribuição, ou em negócios em que a proximidade dos mercados - clientes ou fornecedores - é um factor-chave da vantagem competitiva. Incluem-se, neste caso, três grupos de empresas:

- as cimenteiras, as vidreiras e as siderurgias, entre outras;

- fabricantes de produtos personalizados sujeitos a pequenas economias de escala - tipografias, materiais de embalagem, etc.;

- negócios em que existe uma componente importante de prestação de serviços, associada ao sistema de fabrico — produtos industriais especiais.

O processo de decisão relativo à localização combina uma análise geográfica da densidade dos clientes com cálculos de economias de escala, custos fixos e economias em transportes. $O$ objectivo é a determinação do número e dimensão optimos das instalações e do território a ser servido.

\subsubsection{Especialização}

Em termos da especialização vão-se apresentar duas situações.

A primeira é ilustrada pela indústria electrónica. Nesta, existem três tipos básicos de negócio: a indústria de desenvolvimento, protótipos e pequenas séries, a 
indústria de componentes e a indústria de montagem. $O$ desenvolvimento da indústria electrónica procura uma configuração para as instalações que optimize a integração das especificidades das três vertentes do negócio anteriormente referidas. Assim, a indústria de desenvolvimento requer boas condições climatéricas e luxuosas infra-estruturas de lazer («courts» de ténis, piscinas, etc), factores necessários à atracção de engenheiros projectistas de muito alto gabarito. Citase, como exemplo, San José, na Califórnia, como uma área que recentemente tem sido objecto de preferência para estas empresas. Por outro lado, a indústria de montagem necessita de mão-de-obra barata e abundante, enquanto a indústria de componentes é de capital intensivo, aspectos que favorecem a fragmentação da empresa mãe em empresas especializadas e a instalação em diferentes locais. Por fim, salienta-se que existe uma dimensão crítica para a separação da empresa, a qual pode implicar que, em certas fases transitórias, seja mais interessante subcontratar ou comprar do que fabricar.

A segunda situação é baseada no conceito de foco que preconiza o estreitamento da gama de exigências colocada às instalações fabris, conduzindo à optimização do desempenho, devido a uma concentração da atenção da gestão e da utilização dos recursos em menos tarefas e prioridades. Na prática, isto traduz-se numa mudança de tipos de fábrica genéricos, exclusivamente orientados para o processo - focagem funcional —, para outros mais específicos, orientados para os produtos, mercados e processos, com preocupações de harmonização e integração destes três componentes. $\mathrm{O}$ conceito de foco desenvolve-se em dois planos: externo e interno, relativamente às instalações. Enquanto que no plano externo se aplica à reorganização de várias instalações distintas, no plano interno concretiza-se no conceito de «plant-within-a-plant». Neste caso, depois de fisicamente separadas as diversas partes de uma instalação em subunidades, são afectadas linhas de produção específicas a cada uma. São também atribuídos a cada subunidade mão-de-obra e pessoal das funções de apoio, dedicados.

\subsubsection{Tecnologia}

\subsubsection{Aspectos gerais}

\section{- Estratégia para a tecnologia do processo}

A estratégia para a tecnologia é constituída por um conjunto de decisões que determinam as potencialidades últimas do processo. Uma boa estratégia é caracterizada pela correcta satisfação de três vertentes. São elas a coordenação das actividades técnicas e operacionais, o suporte da estratégia competitiva pelo potencial tecnológico e a consistência na dimensão tempo, de modo a que exista 
uma continuidade da capacidade tecnológica periódica, mas coerentemente renovada, por forma a reforçar e expandir a posição competitiva do negócio.

\section{- Significado de tecnologia}

Hoje em dia, utiliza-se a palavra tecnologia com um significado algo amplo. Antes de mais, é importante ver como e por quem.

Por exemplo, os analistas, os manipuladores de dados e as organizações governamentais tendem a adoptar uma perspectiva macroeconómica, em que as tecnologias são classificadas por indústria, ou por produtos fabricados, nomeadamente: papel, computadores, aço, petroquímicas, bens consumíveis e bens duráveis.

Ainda externamente à empresa, os fornecedores de equipamentos, cujo produto é a tecnologia de processamento, autoclassificam-se e, consequentemente, também à tecnologia, como fabricantes de máquinas-ferramenta (classe mais geral) e como fabricantes de máquinas específicas (por exemplo, impressão de códigos em semi-condutores).

Internamente à empresa vão distinguir-se, de seguida, as perspectivas de três grupos: os especialistas, os gestores de operações e os gestores de topo.

\subsubsection{A perspectiva dos especialistas}

A este nível a tecnologia envolve basicamente a conversão de materiais, pela qual os equipamentos e a força de trabalho interagem directamente com os materiais, com a finalidade da sua transformação em produtos acabados.

Por vezes, corre-se o perigo dos especialistas se identificarem primeiramente com as tecnologias relativas à sua área de especialidade e, somente depois, com a organização a que prestam serviços.

Os especialistas envolvem-se, durante a maior parte do seu tempo, com pequenas decisões assumidas individualmente, pela sua reduzida expressão económica, mas que, na ausência de directrizes claras, de padrões de actuação e de uma preocupação de análise do enquadramento e contribuição para o conjunto, poderão tornar a empresa sua refém.

Finalmente, importa referir que a máxima de que os engenheiros não dão, geralmente, bons gestores tem sido contrariada, com sucesso, pelo exemplo das empresas industriais japonesas e alemãs.

- Engenheiros de processo ou de fabrico

Os engenheiros de fabrico lidam com as tecnologias de transformação das matérias-primas em produtos acabados, através da alteração das suas proprieda- 
des físicas e/ou aparência. A sua função inclui a selecção e a adaptação da tecnologia de fabrico, a qual é função dos materiais usados, dos produtos requeridos e da estratégia a seguir. Na seleç̧ão da tecnologia é usado um conjunto de competências, composto pela ciência dos materiais e por análises mecânicas e económicas.

\section{- Engenheiros industriais}

Os engenheiros industriais actuam sobre a concep̧̧ão do posto de trabalho (estudo dos métodos e tempos), implantação física dos equipamentos (estudo do «layout») e fluxos de materiais. O âmbito da sua acção concretiza-se, pois, nos seguintes aspectos: concepção das tarefas desempenhadas por indivíduos e postos de trabalho; concepção dos fluxos físicos entre postos de trabalho e entre estes e áreas de armazenamento. Os seus principais objectivos são a maximização da eficiência da força de trabalho e da utilização dos equipamentos.

Uma das suas principais actividades é a dinamização do processo de melhoramento contínuo do funcionamento da fábrica, através da implementação de alterações ao produto, aos equipamentos, à forma de execução e aos fluxos, questões que também se consideram de natureza tecnológica.

\section{- Outros especialistas}

O gestor de materiais desenvolve, entre outras, as seguintes actividades: compras, gestão de inventários, controle de fluxos e manuseamento de materiais. $A$ sua interacção com a tecnologia, enquanto suporte do processo de transformação, faz-se basicamente a nível do manuseamento dos materiais (empilhadores, AGV's, transportadores, armazéns automáticos, etc). Relativamente às não menos importantes actividades de gestão e de controle, existe uma forte componente de utilização das ditas tecnologias de informação.

O gestor de informação é uma função recente, cujas actividades estavam distribuídas por outras funções. A sua afirmação como função independente deriva, entre outros, do grau de complexidade, do tipo e da dimensão da organização, bem como do nível de informatização. Esta actividade usa como principal ferramenta os sistemas informáticos na gestão do processo de fabrico, nomeadamente nas vertentes de comunicação, ligação e controle de equipamentos e processos.

\subsubsection{A perspectiva dos gestores de operações}

Muitos dos gestores de operações evoluíram a partir de uma carreira de técnico especialista. Geralmente, os gestores de operações entendem a tecnologia, 
simplesmente, como um meio para se alcançarem as metas de produção e de «performance». Contudo, há três aspectos relativos à tecnologia que devem ser endereçados pelo gestor de operaçôes: (1) como funciona o processo (características técnicas, flexibilidade, balanceamento e compromissos), (2) a sua avaliação $e$ «performance» económica e (3) os principais problemas relativos à sua gestão.

A fim de optimizar o seu relacionamento com os especialistas, os gestores de operações devem possuir um entendimento básico da tecnologia de produção e das suas características de funcionamento.

As actividades desempenhadas pelo gestor de operações têm diferente relevância e importância, consoante os tipos de sistema de fabrico, a saber: o Projecto, o «Jobbing», a Produção em Lotes, a Linha de Produção e o Processo de Fluxo Contínuo. Cita-se, como exemplo, a caracterização do principal desafio do gestor de operações. Enquanto que no «jobbing» assumem particular importância a utilização da força de trabalho, a rapidez da resposta, a eliminação de estrangulamentos, o sequenciamento e as estimativas de tempos e custos (orçamentos), na Linha de Produção o foco passa a incidir na melhoria da produtividade, no ajustamento da força de trabalho ao programa de produção («mix» e quantidade), no balanceamento da linha e na minimização de custos. Conclui-se então que, embora o envolvimento do gestor de operações com a tecnologia seja variável, consoante o tipo de operações, não deixa de ser uma constante.

\subsubsection{A perspectiva dos gestores de topo}

Em termos de tecnologia, os gestores de topo preocupam-se com a extensão do suporte que esta proporciona a requisitos específicos do negócio, por exemplo: às necessidades dos clientes, às restrições financeiras, aos novos ciclos de desenvolvimento dos produtos, etc. Os gestores de topo devem procurar garantir a consistência e a articulação do sistema de fabrico com as restantes áreas funcionais, ao contrário dos gestores de operações que se preocupam essencialmente com aspectos intrínsecos ao sistema produtivo.

Os gestores de topo provenientes de áreas técnicas têm tendência para pensar mais em termos técnicos do que em termos de gestão. Por outro lado, os gestores com formação em gestão têm tendência a ser demasiado superficiais na abordagem técnica ou, em alternativa, delegam essas importantes decisões.

A perspectiva tradicional da tecnologia de fabrico que os gestores de topo possuem caracteriza-se por um conjunto de aspectos que se passará a expor. Primeiramente, a tecnologia é entendida como algo de específico e do âmbito dos níveis inferiores e operacionais da pirâmide de gestão, existindo uma demissão de responsabilidades face às opções tecnológicas. Por outro lado, os vários projectos 
existentes são entendidos como acções individuais e susceptíveís de ser separadamente analisados e avaliados, sendo ignorada a dimensão sistémica do aparelho produtivo. Também o valor que a tecnologia possui é exclusivamente relacionado com a maior ou menor habilitação para o fabrico dos produtos requeridos, sendo frequentemente esquecida a contribuição para a posição competitiva do negócio, através do impacto na concepção do produto, nos materiais usados, na força de trabalho e na gestão da fábrica. Quanto ao processo de avaliação de projectos de mudança tecnológica, verifica-se uma redução dos critérios aos de carácter financeiro e com um excessivo enfoque no curto prazo. Relativamente ao processo de mudança, os gestores de topo demonstram, normalmente, preferência pela inovação, caracterizada por fortes investimentos e por um corte radical com o passado. É assim ignorado o papel desempenhado pelo processo de melhoramento contínuo, quer em termos de complementaridade face à inovação, quer na contribuição para a melhoria da competitividade. Finalmente, o entendimento da função de gestão de topo como sendo de carácter geral, em que apenas se relevam os grandes planos e as generalidades, é limitador de uma atitude concertada face aos aspectos tecnológicos.

\subsubsection{Integração vertical}

\subsubsection{Aspectos gerais}

As decisões sobre Integração Vertical também são genericamente referenciadas como Posicionamento do Processo, por analogia com o Posicionamento do Produto, o qual é relativo às decisões no âmbito da estratégia de «Marketing» («mix», «design», gama, «pricing», distribuição, etc). O posicionamento do processo define as fronteiras da empresa para as suas actividades e o relacionamento com a envolvente (fornecedores, distribuidores e clientes). Trata ainda do processo de mudança destas relações e do respectivo impacto em termos da posição competitiva do negócio, do ponto de vista do aparelho produtivo.

A integração vertical pode tomar duas direç̧ões. A integração a montante, que é encarada como uma acção defensiva, pretende melhorar o controle sobre os fornecedores. A integração a jusante é um movimento ofensivo que tem por finalidade o melhoramento do controle do mercado. Esta última é, normalmente, a opção de integração preferida pelas empresas, sendo três vezes mais escolhida do que a anterior.

As decisões sobre a extensão da integração referem-se ao número de elos da cadeia comercial esquematizada na Figura 3, que serão abrangidos pela acção de integração. 
Fig. 3

ELOS DA CADEIA COMERCIAL

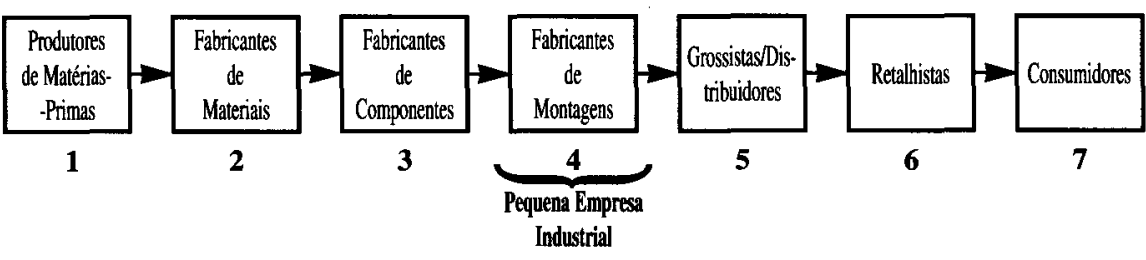

Fonte: Hayes, 1984

Um terceiro tipo de decisões nesta temática refere-se ao balanceamento de capacidades entre os vários estágios produtivos, depois de uma acção de integração. Como exemplo, cita-se o caso de aquisição de um fornecedor. Será que este deverá passar a ser um fornecedor cativo, isto é, que forneça exclusivamente a nova empresa-mãe? Será que a empresa-mãe se deverá abastecer em $100 \%$ das suas necessidades neste novo fornecedor interno? Tais opções são delicadas e poderão deteriorar as relações com outros fornecedores ou clientes.

\subsubsection{Implicações para o negócio}

\section{- Financeiras}

Quanto mais a montante as empresas se situarem na cadeia comercial, tanto mais estreita é a sua gama de produtos, o que permite o fabrico de lotes de maior dimensão utilizando métodos de produção contínua, de capital-intensivo. Nesta situação, as economias de escala deverão ser significativas, pelo que a dimensão económica mínima da fábrica deverá aumentar. $\mathrm{O}$ aumento da dimensão da fábrica também implica um acréscimo nos custos de encargos financeiros, de depreciação e de manutenção. Consequentemente, o ponto crítico destas empresas é superior ao das situadas a jusante na cadeia comercial e a rácio Vendas/Activos apresenta valores menores.

As empresas, na situação do parágrafo anterior, têm dificuldade em alterar taxas de produção, pelo que a resposta habitual, a situações de diminuição da procura, é a diminuição dos preços, com vista à reposição do equilíbrio. No entanto, é vulgar que pequenas alterações nos preços ou na produção reduzam significativamente os lucros. 


\section{- Tecnológicas}

A possibilidade de aquisição de competências na tecnologia de fabrico de componentes críticos, no desenvolvimento de novos produtos e a possibilidade de antecipação ao processo de mudança tecnológica têm sido muitas vezes apontadas como justificação de integrações verticais. Embora muitas vezes se pense que as grandes mudanças derivam de alterações do mercado, o certo é que, na prática, tem-se demonstrado a proveniência destas da retaguarda e, nomeadamente, de alterações tecnológicas e de materiais. É o caso da substituição das válvulas pelos transistores e das calculadoras mecânicas pelas electrónicas. Também, na maior parte das vezes, a realidade tem demonstrado que as empresas, detentoras de tecnologias desactualizadas, têm-se mostrado incapazes do domínio das novas tecnologias emergentes, tornando-se completamente obsoletas. Cita-se, em Portugal, o exemplo de mudança de tecnologia das máquinas de escrever (mecânica para electrónica) que levou à falência um importante fabricante nacional.

\section{- Escala e balanceamento}

Se um fornecedor adquirido apresentasse diferentes economias de escala das do seu comprador, a tentativa de acerto de capacidades podia tornar-se fortemente penalizadora elou ineficiente. Por exemplo, embora uma empresa de montagem pudesse ser dimensionada para as necessidades do mercado, isso não significava que um dos seus fornecedores de componentes obedecesse aos mesmos critérios de dimensionamento, pois isso poderia torná-lo demasiadamente pequeno, em relação aos seus concorrentes, para que fosse eficiente. Por outro lado, a dinamização de uma força de vendas $e$ a angariação de novos clientes provocariam, quer um acréscimo de custos que era suposto eliminar ou reduzir pela integração (os de «marketing» e vendas), quer potenciais conflitos de interesse com o cliente empresa-mãe.

\subsubsection{Vantagens e desvantagens}

\section{- Vantagens}

As empresas são normalmente atraídas para a integração vertical, ou pelo potencial aumento da margem de lucro, ou pela melhoria esperada no controle do negócio.

O aumento da margem de lucro resultaria da absorção da do fornecedor ou do cliente, da eliminação dos custos de transacção (associados à compra ou ao «mar- 
keting»), da eliminação dos custos de logística, da redução dos custos de projecto e de «set up» e, finalmente, do aumento da fiabilidade das previsões.

A melhoria do controle implica considerações de carácter mais subjectivo, nomeadamente a suposição de que a gestão integrada dos vários negócios, com objectivos, restrições e estratégias comuns resultaria num maior benefício. Por outro lado, a optimização do controle deveria também resultar numa melhor protecção contra fornecedores e clientes críticos, numa redução das práticas agressivas da concorrência, numa melhor cooperação e comunicação e num melhor controle da conformidade relativa à qualidade, prazos, «mix» e quantidades.

\section{- Desvantagens}

Por outro lado, a prática mostra que, por vezes, a integração vertical resulta num aumento dos custos e numa perda de controle.

As razões apontadas para o aumento dos custos podem resultar da ausência de economias de escala nos materiais comprados e no fabrico, da falta de experiência de gestão do novo negócio e da atribuição de um estatuto inferior à empresa adquirida, podendo este último aspecto traduzir-se numa afectação de recursos insuficiente para a actividade.

A perda de controle poderá derivar de diferentes estruturas de produtos e processos, de políticas e filosofias de operação incompatíveis, de um processo de tomada de decisão mais lento e burocratizado, de um choque cultural, do aumento da dimensão da organização e de um fluxo de informação mais lento. A propósito, conta-se a história daquele grupo em que duas empresas suas se relacionavam através de um intermediário externo. Quando confrontada com a possibilidade da eliminação deste, a gestão da empresa-cliente recusou frontalmente, argumentando que isso deterioraria prazos e preços...

\subsubsection{Alternativas à integração vertical}

- Posse de inventários

A potencial ameaça de perturbações, causadas por fornecedores pertencentes a grupos concorrentes, pode ser ultrapassada pela detenção de «stocks» dos artigos/materiais em questão. Estes ajudarão a ultrapassar atrasos de entregas e falhas temporárias.

As desvantagens são o encargo financeiro resultante, a perda de flexibilidade face à mudança e a potencial deterioração dos inventários. 
- Alterações das relações com fornecedores/clientes

As relações tradicionais com os fornecedores/clientes desenvolvem-se em cenários de curto prazo, caracterizados por uma forte ênfase na redução de preços e pela existência de múltiplas fontes de aprovisionamento, concorrentes entre si. Esta é a alternativa que resulta na maximização da flexibilidade, por oposição à maximização do controle, derivada da integração vertical.

Os Japoneses, contudo, preferem uma situação intermédia em que são efectuados acordos de longo prazo que conferem aos fornecedores o estatuto de parceiros. Nesta situação, o fornecedor fica a ganhar, pois consegue uma estabilização da procura, um estatuto preferencial e apoio do cliente, inclusive financeiro. Por sua vez, o cliente tem como vantagens um certo controle do fornecedor que garante o cumprimento dos prazos e da qualidade. $\mathrm{Na}$ indústria automóvel também é vulgar negociarem-se reduções constantes e progressivas dos preços.

- «Joint Ventures», licenciamento e contratos de longo prazo

Estes são alguns dos meios de formalização e fixação do quadro legal de enquadramento dos acordos de longo prazo. Se, por um lado, requerem um investimento menor do que a integração vertical, por outro, também não substituem a confiança e o espírito de cooperação que deverão ser empenhados numa ligação deste tipo.

\section{- Integração do investimento}

Denomina-se assim a redução de custos e melhoria do controle dos fornecedores, conseguida através de um investimento específico, por parte do cliente, em ferramentas e máquinas que são colocadas no fornecedor, mas sem que sejam assumidas quaisquer responsabilidades operacionais na empresa.

Este investimento também pode ser efectuado por um fornecedor, em «stocks» dos seus produtos existentes no cliente.

\subsection{Metodologia de implementação da estratégia integrada da produção}

Existe uma vasta bibliografia acerca da temática estratégia empresarial. Contudo, são escassas as perspectivas que facultam um conjunto de métodos, principios e de procedimentos que permitam definir uma abordagem consistente e aplicada da temática estratégia da produção. De seguida apresentaremos uma dessas raras perspectivas (Hill, 1985). 


\subsubsection{A ligação entre a produção e a estratégia do negócio}

A metodologia de $T$. Hill baseia-se na chamada interface estratégica «marketing»-produção. Esta consta de cinco passos que providenciam as ferramentas analíticas necessárias ao debate interno à empresa e que suportam as consequentes acções a serem tomadas. $O$ relacionamento entre esses diversos estádios caracteriza-se por ser iterativo com ciclos de «feedback» entre todos eles. Isto significa que não há relações lineares e determinísticas, mas sim reformulações continuadas das várias fases, à medida que se aplica o procedimento. Salienta-se que também as escolhas referentes às duas últimas fases - a estrutura e a infra-estrutura da produção - deverão ser reformuladas quando há alterações nos estádios anteriores, ao contrário da predisposição que normalmente existe para negar, ou dificilmente aceitar, quer as mudanças nos elementos da estratégia da produção, quer o seu impacto na estratégia do negócio.

Os restantes elementos inovadores da abordagem são os «order-winners». Definem-se como os critérios que promovem o ganho de encomendas para cada produto, em cada mercado e em cada instante de tempo, face à concorrência. Estes são os factores conciliadores das estratégias de «marketing» e da produção e que servem simultaneamente para a execução da focagem de ambas.

Têm-se, então, as seguintes cinco etapas:

1. Definição dos objectivos para o negócio

2. Determinação das estratégias de "marketing», para que se alcancem esses objectivos

3. Identificação dos «order-winners»

4. Fixação do modo mais adequado de fabrico para cada um dos produtos em estudo - escolha da estrutura de fabrico

5. Escolha da infra-estrutura requerida para suportar a produção

O Quadro IV ilustra algumas das opções existentes em cada uma das fases. 


\section{Quadro IV}

ESTRUTURA DE ENQUADRAMENTO DA ESTRATÉGIA DA PRODUÇÃO NA ESTRATÉGIA DO NEGOCIO

\begin{tabular}{|c|c|c|c|c|}
\hline Fase 1 & Fase 2 & Fase 3 & Fase 4 & Fase 5 \\
\hline \multirow{2}{*}{$\begin{array}{c}\text { Objectivos do } \\
\text { negócio }\end{array}$} & \multirow{2}{*}{$\begin{array}{l}\text { Estratégia de } \\
\text { «Marketing» }\end{array}$} & \multirow[b]{2}{*}{ «Order-winners» } & \multicolumn{2}{|c|}{ Estratégia da produção } \\
\hline & & & $\begin{array}{c}\text { Escolha } \\
\text { do processo }\end{array}$ & Infra-estrutura \\
\hline $\begin{array}{l}\text { - crescimento } \\
\text { - sobrevivência } \\
\text { - lucro } \\
\text { - ROI } \\
\text { - outros }\end{array}$ & $\begin{array}{l}\text { - mercados e se- } \\
\text { gmentos } \\
\text { - gama } \\
\text { - «mix» } \\
\text { - volumes } \\
\text { - standardização } \\
\text { ou personaliza- } \\
\text { ção } \\
\text { - nível de inovação } \\
\text { - seguidor ou líder }\end{array}$ & $\begin{array}{l}\text { - preço } \\
\text { - conformidade } \\
\text { qualidade } \\
\text { - entrega } \\
\text { cumprimento } \\
\text { prazo } \\
\text { - gama de cores } \\
\text { - gama de produtos } \\
\text { - concepção } \\
\text { - imagem de marca } \\
\text { - apoio técnico }\end{array}$ & $\begin{array}{l}\text { - escolha entre pro- } \\
\text { cessos alternati- } \\
\text { vos } \\
\text { - compromissos } \\
\text { relativos à esco- } \\
\text { lha } \\
\text { - papel desempe- } \\
\text { nhado pelo in- } \\
\text { ventário no pro- } \\
\text { cesso } \\
\text { - posicionamento } \\
\text { do processo } \\
\text { - capacidade } \\
\text { dimensão } \\
\text { «timming» } \\
\text { localização }\end{array}$ & $\begin{array}{l}\text { - apoio funcional } \\
\text { - sistemas de pla- } \\
\text { neamento e con- } \\
\text { trole da produção } \\
\text { - engenharia do } \\
\text { sistema produ- } \\
\text { tivo } \\
\text { - garantia e contro- } \\
\text { le da qualidade } \\
\text { - procedimentos } \\
\text { administrativos } \\
\text { - estruturação do } \\
\text { trabalho } \\
\text { - estrutura organi- } \\
\text { zacional } \\
\text { - sistemas de pa- } \\
\text { gamentos }\end{array}$ \\
\hline
\end{tabular}

Fonte:Hill, 1985

Obs: Na realidade, o procedimento envolve a formulação e a reformulação de todos os passos, até que seja obtida a solução possível e globalmente satisfatória.

\subsubsection{A dinâmica da interface estratégica do negócio}

O objectivo de todo este procedimento é a elaboração da Estratégia Integrada da Produção para o negócio (fases 4 e 5). Para tal, é necessário que exista um relacionamento com os objectivos do negócio, estabelecido através da estratégia de «marketing». Um dos principais aspectos desta consiste na correcta e objectiva identificação dos produtos, «mix» e quantidades a colocar nos diversos mercados e segmentos, quer sejam novos produtos, quer se trate de produtos já existentes. Deverá ainda incluir considerações relevantes sobre a personalização das gamas, inovação e desenvolvimento dos produtos e definição da táctica de liderança ou seguimento a utilizar. De seguida, deverão analisar-se os factores que, 
para um dado produto, num dado mercado e num dado período de tempo, fazem o cliente decidir-se a favor do nosso produto (os «order-winners»), bem como aqueles que inicialmente levam o cliente a considerar o nosso produto como uma potencial alternativa (os «qualifiers»). Deverão ser analisadas várias perspectivas do mercado, devendo evitar-se a dominância da perspectiva do «marketing» que, sem dúvida, é importante, mas não é única.

«A posteriori», deverá ponderar-se a possibilidade do nosso sistema de fabrico satisfazer as exigências do mercado, isto é, fabricar os produtos nas condições explicitadas anteriormente pelos «order-winners» e «qualifiers», de modo a que se apresentem com uma vantagem competitiva face à concorrência. Se isto não for possível, será que existem meios e vontade de mudar o sistema de fabrico (estrutura e/ou infra-estrutura), ou será que é a estratégia de marketing que tem que mudar, ou vamos ajustar os dois, ou vamos, finalmente, ignorar e deixar tudo na mesma? É caso para se dizer: uma de quatro! Como observação final, salienta-se que a última opção, desde que conscientemente tomada, é tão válida como qualquer uma das outras.

\subsection{3. «Order-winners» $e$ «ualifiers»}

O seu significado foi definido no parágrafo anterior. Pode-se, contudo, acrescentar que, enquanto um «qualifier» não faz ganhar uma encomenda, o mesmo já não se pode dizer dos «order-winners» $(O W)$. Estes são decisivos para tal. No entanto, se não forem verificados, os «qualifiers» podem transformar-se em «order-loosers», ou seja, em factores que sistematicamente ocasionem a perda de encomendas para a empresa. Saliente-se ainda que, enquanto os «qualifiers» são tratados de modo qualitativo, os «order-winners» deverão possuir ponderações associadas que totalizem $100 \%$ em cada período de tempo, podendo variar os valores parciais de período para período.

No Quadro V vão ilustrar-se estes conceitos com um caso real, bem como a sua dinâmica de funcionamento. 
Quadro V

ESTUDO DE CASO SOBRE A INTRODUÇÃO DAS TELEVISÕES NIPÓNICAS NO MERCADO EUROPEU

\begin{tabular}{|c|c|}
\hline Fase & Descrição \\
\hline \multirow[t]{2}{*}{ Situação 1} & $\begin{array}{l}\text { «No início da década de } 70 \text { o mercado europeu das televisões a cores era } \\
\text { dominado pelos fabricantes do velho continente. A qualidade era má, pois } \\
\text { imperava um elevado índice de falhas e os preços eram elevados, até que ... }\end{array}$ \\
\hline & $\begin{array}{ll}\text { «order-winner» } & \text { preço } \\
\text { «qualifier»: } & \text { qualidade }\end{array}$ \\
\hline \multirow[t]{2}{*}{ Situação 2} & $\begin{array}{l}\text {... foram introduzidos os televisores japoneses que apresentavam um ser- } \\
\text { viço muito superior, o qual se traduzia em muito menos falhas em serviço, } \\
\text { menor incómodo e menor necessidade de manutenção. Os fabricantes } \\
\text { europeus começaram a perder quota, até que ... }\end{array}$ \\
\hline & $\begin{array}{ll}\text { «order-winner»: } & \text { qualidade } \\
\text { «qualifier»: } & \text { preço }\end{array}$ \\
\hline \multirow[t]{2}{*}{ Situação 3} & $\begin{array}{l}\text {... no princípio da década de } 80 \text { reagiram, melhorando o nível de perfor- } \\
\text { mance dos seus produtos até ao standard do mercado. Reestabeleceu-se o } \\
\text { equilíbrio no mercado, mas com uma diferente repartição de quotas e num } \\
\text { nível competitivo superior». (Hill, 1985) }\end{array}$ \\
\hline & $\begin{array}{ll}\text { «order-winner» } & \text { preço } \\
\text { «qualifier»: } & \text { qualidade }\end{array}$ \\
\hline Conclusão & $\begin{array}{l}\text { O sistema de fabrico deve ser capaz de verificar os critérios que permitem } \\
\text { entrar no, ou manter o mercado - os «qualifiers». Contudo, estes sozi- } \\
\text { nhos não permitem o ganho de encomendas. Apenas evitam a perda, «a } \\
\text { priori», das encomendas para a concorrência. Uma vez alcançados os } \\
\text { «qualifiers», o sistema de fabrico deve concentrar-se nos «order-winners» } \\
\text { e tentar que os seus sejam superiores aos da concorrência. Os «order-win- } \\
\text { ners» e os «qualifiers» são factores dinâmicos que poderão evoluir, adap- } \\
\text { tando-se a novas situações emergentes. }\end{array}$ \\
\hline
\end{tabular}

Devem salientar-se dois aspectos na definição dos «order-winners» e dos «qualifiers». O primeiro destaque vai para a clareza como deverão ser definidos, de modo a serem evitadas confusões de semântica. $\mathrm{O}$ segundo ponto reporta-se à não ambiguidade dos conceitos. Por exemplo, melhorar o serviço prestado, ou melhorar a qualidade são afirmações de carácter geral que não servem para suportar uma opção estratégica, por serem pouco claras e ambíguas. Refira-se, como curiosidade, que o tipo de declaração de intenção ambígua e mal definida prolifera na estratégia empresarial, para seu grande prejuízo. Existem outras confusões vulgares a evitar como, por exemplo, cumprir um prazo «versus» dar um prazo 
curto e qualidade (verificar a conformidade com uma especificação) «versus» «design" (criar uma especificação).

Nunca é de mais referir que uma estratégia e respectivos «order-winners» e «qualifiers» são função das dimensões empresa, tempo e mercado. Por isso, não podem ser definidos, nem em absoluto, nem emprestados para situações diferentes das da sua concepção. O Quadro VI ilustra a aplicação prática dos «order-winners» e «qualifiers».

\section{Quadro VI}

Volumes semanais, pesos dos «order-winners» e «qualifiers» para três produtos representativos de três famílias

\begin{tabular}{|c|c|c|c|c|c|c|c|c|c|}
\hline \multirow{3}{*}{ «Order-winning» } & \multicolumn{9}{|c|}{ Produtos, Escalas de Tempo e Pesos } \\
\hline & \multicolumn{3}{|c|}{ Produto A } & \multicolumn{3}{|c|}{ Produto B } & \multicolumn{3}{|c|}{ Produto C } \\
\hline & 1993 & 1994 & 1996 & 1993 & 1994 & 1996 & 1993 & 1994 & 1996 \\
\hline $\begin{array}{l}\text { Capacidade de } \\
\text { concepção }\end{array}$ & & & & 40 & & & & & \\
\hline $\begin{array}{l}\text { Modificações no } \\
\text { projecto }\end{array}$ & & & & & 20 & & 20 & & \\
\hline Apoio técnico & & & & 20 & 20 & & 20 & & \\
\hline Fornecedor local & 10 & & & 10 & 10 & 10 & 20 & & \\
\hline $\begin{array}{l}\text { Existência de } \\
\text { fornecedor }\end{array}$ & 10 & 60 & 90 & 10 & 20 & 30 & & 30 & 30 \\
\hline Preço & 60 & 40 & 10 & 20 & 30 & 60 & 30 & 40 & 40 \\
\hline $\begin{array}{l}\text { Entrega } \\
\qquad \text { - rapidez }\end{array}$ & 20 & & & & & & 10 & 30 & 30 \\
\hline - fiabilidade & QQ & Q & & & QQ & QQ & QQ & QQ & QQ \\
\hline $\begin{array}{c}\text { Conformidade } \\
\text { (qualidade) }\end{array}$ & Q & Q & Q & & QQ & Q & Q & Q & Q \\
\hline Volumes semanais & 2500 & 1500 & 50 & & 300 & 700 & 3000 & 4000 & 4000 \\
\hline
\end{tabular}

Fonte:Hill, 1985

Obs: $Q$ representa um «qualifier» e $Q Q$ um «qualifier» muito sensível, isto é, um potencial «order-looser»

Este quadro, embora possua uma aspecto simples, poderá gerar alguma polémica no seu preenchimento. Primeiro, há que escolher os «order-winners» e os «qualifiers», consoante previamente explicado. Seguidamente, deverá decidir-se 
quais os intervalos de tempo a considerar em função de acontecimentos cuja ocorrência seja relevante e se possa antever. Estes acontecimentos estão, normalmente, associados ao ciclo de vida dos produtos nos respectivos mercados $\mathrm{e}$ às consequentes variações de volume, em certos períodos. Há então que analisar o impacto destas variações de volume nas ponderações dos diversos «order-winners» e fazer os ajustamentos necessários. Salienta-se que os «qualifiers» poderão também sofrer alterações. Refira-se ainda que os pesos a atribuir aos «order-winners» deverão ser cuidadosamente analisados e não deverão ser distribuídos de qualquer maneira, apenas para justificar o cumprimento do procedimento.

Outro dos aspectos mais importantes do que foi dito é que, as mudanças que os «order-winners» e os «qualifiers» implicam na organização, devem efectivamente ocorrer, isto é, as diversas áreas funcionais deverão estar preparadas para alterar e, de facto, alterarem os seus procedimentos quando tal for requerido.

Finalmente, salienta-se a iteratividade de todo o processo. Isto significà que se deverão rever continuadamente todos os passos até se alcançar uma solução realista e que traduza o melhor consenso para o negócio como um todo. É também preferível que se fixem metas comedidas, a atingir faseadamente, através de pequenos mas seguros progressos, em alternativa a objectivos ambiciosos e impossíveis de alcançar na prática.

\subsection{Síntese do parágrafo}

\subsection{1. «Outputs» da estratégia da produção}

Destacam-se principalmente dois tipos de «outputs»:

1. Revisão das implicações para a estrutura e infra-estrutura do aparelho produtivo resultantes da necessidade de se suportar o fabrico de um conjunto de produtos, numa dada «mix» e num certo volume. Como consequência imediata tem-se a avaliação do nível de desempenho do sistema de fabrico existente face ao que se requer para satisfazer os «order-winners» determinados.

Deste modo, a produção tem possibilidades de facultar uma resposta apropriada às diferentes solicitações do mercado, em lugar de oferecer uma única possibilidade de satisfação para um vasto espectro de requisitos.

2. Determinação do conjunto de investimentos requerido e respectiva escala de tempo, no âmbito do domínio de actividade e, portanto, de modo inte- 
grado na estratégia para o negócio. Existe, pois, uma mudança dos critérios de avaliação do investimento, de uma base funcional, para uma plataforma de compromisso a nível do interesse e da estratégia da organização.

A empresa é agora capaz de avaliar as consequências, para o negócio, de eventuais divergências na interface «marketing»/produção e de evitar danos maiores, usando esta informação nas decisões estratégicas.

Resumindo, tem-se fundamentalmente, como resultado de uma estratégia de produção adequada, uma resposta do sistema de fabrico devidamente focada nos aspectos, de facto, relevantes e uma racionalização do investimento com a consequente optimização da utilização dos recursos (sempre limitados), em benefício da empresa vista como um todo.

\subsubsection{Avaliação da estratégia da produção}

Alguns autores (Hayes, 1984) defendem que a Estratégia da Produção deverá ser avaliada segundo duas vertentes: quanto à consistência interna e externa $\mathrm{e}$ quanto à contribuição para a vantagem competitiva.

\section{Consistência}

Deverá verificar-se entre a estratégia da produção e:

- a estratégia para a organização;

- as restantes estratégias funcionais do domínio;

- a envolvente do negócio no que se refere à disponibilidade de recursos, restrições governamentais, comportamento competitivo, etc).

Também as diferentes categorias de decisão referentes à estratégia da produção deverão mostrar consistência, quer entre elas, quer em relação a cada uma, isoladamente, ao longo do tempo e através dos diversos níveis da hierarquia de gestão.

\section{Contribuição para a vantagem competitiva}

Esta contribuição deverá ser avaliada com base no sucesso obtido pela dinamização das seguintes acções:

- explicitação dos compromissos assumidos (nas áreas de decisão), permitindo a fixação e divulgação das prioridades relevantes para o negócio;

- direccionamento da atenção para as oportunidades que complementam a estratégia do negócio; 
- promoção da clarificação da estratégia da produção para o domínio, com o objectivo de concretização de todo o seu potencial;

- suporte do desenvolvimento das competências requeridas pela produção no futuro.

\section{CONCLUSÕES}

Pretende-se que este artigo contribua para a divulgação e afirmação da dimensão estratégica da produção, nas empresas que ainda ignoram esta componente da gestão do aparelho produtivo e também naquelas que, já numa fase mais avançada, procuram dar consistência a esta vertente da gestão. No entanto, são necessários muito empenho e persistência para que se obtenham resultados num campo como este, apenas aparentemente simples. $O$ teste-chave do desempenho da estratégia da produção é concretizado pelo efectivo grau de suporte que a gestão de operações quotidianamente faculta à estratégia empresarial, com vista ao alcance dos objectivos da organização.

Espera-se ainda uma contribuição para o complemento da formação dos jovens quadros do futuro, para que estes não venham a manifestar, no seu desempenho, algumas das deficiências apontadas anteriormente e para que possam incutir nas empresas um novo dinamismo e uma superior competitividade, face às mutações da envolvente, tal como é defendido pela política industrial portuguesa.

É também nosso objectivo promover a sensibilização, em geral, para diferentes atitudes de gestão que se têm demonstrado eficientes em organizações de vanguarda, bem como divulgar formas concrectas de efectiva articulação, implementação e utilização dessas ideias no seio das empresas.

Finalmente, o autor espera poder proporcionar um modesto contributo para um emprego mais rigoroso de alguns vocábulos e conceitos que muitas vezes são mal utilizados, quer por falta de esclarecimento, quer pela existência de várias tendências, de significados conflituosos entre si. A semântica escolhida foi sempre aquela que se julga actualmente predominante. Por outro lado, também se efectuou um esforço no sentido de se promoverem abordagens estruturadas, enquadradas e consolidadas das temáticas expostas e discutidas, pois tem-se constatado essa ausência na vida prática, quer em termos de empresas, quer em termos de cursos leccionados em acções de formação. 


\section{BIBLIOGRAFIA}

ARMOUR, Henry O., and TEECE, David J., 1980, «Vertical Integration and Technical Innovation», Review of Economics and Statistics, vol. 62, N 3, August, p. 470-474.

HAYES, R. and ABERNATHY, William J., 1980, «Managing Our Way to Economic Decline», Harvard Business Review, July-August, p. 67-77

HAYES, R. and WHEELWRIGHT, S., «Restoring our Competitive Edge», 1984, J. Wiley \& Sons, USA

HILL, T., «Manufacturing Strategy», 1985, The Macmillan Press Ltd, London

HUGHES, J., 1990, «A Modern Approach to Manufacturing Management», The Open University, Milton Keynes

PORTER, M., 1980, «Competitive Strategy», Free Press, New York

SHAPIRO, Benson P., 1977, «Can Marketing and Manufacturing Coexist?», Harvard Business Review, September-October, p. 104-114

VILAS-BOAS DA SILVA, J.M., 1993, «Modernos Desafios à Gestão da Aparelho Produtivo», Gestão e Desenvolvimento n. ${ }^{\circ}$ 2, UCP/CRV/UUDS, p. 77-96. 